\title{
OPTIMASI JUMLAH PRODUKSI BAJA RINGAN MENGGUNAKAN METODE LINEAR PROGRAMMING
}

\author{
Willis Thedra ${ }^{1}$ dan Iwan B. Santoso ${ }^{2}$ \\ ${ }^{1}$ Program Studi Sarjana Teknik Sipil, Universitas Tarumanagara, Jl. Letjen S. Parman No.1 Jakarta \\ Willis.325160140@stu.untar.ac.id \\ ${ }^{2}$ Program Studi Sarjana Teknik Sipil, Universitas Tarumanagara, Jl. Letjen S. Parman No.1 Jakarta \\ Iwsantoso@hotmail.com
}

Masuk: 15-01-2020, revisi: 18-02-2020, diterima untuk diterbitkan: 26-02-2020

\begin{abstract}
Linear programming can analyze various constraints related to the real conditions in the company and provide the best solution. In this research, light steel production planning is carried out for 6 working days, where there are 4 types of mild steel products with different thickness. With this method, production scheduling is obtained per day and the profit gained during the week is, when the price of raw materials is normal, a profit of Rp 179,005,800 was obtained; when the price of raw materials decreased, a profit of $R p$ 171,143,000 was obtained, and when the price of raw materials rose, a profit of Rp 205,766,400 was obtained. In this study several scenarios were conducted, such as scenario 1, the machine used must not be damaged on the first day of production because the production target will not be achieved, then for scenario 2 an increase in the number of requests was $10 \%$ and for scenario 3 the reduction in working hours was obtained for a maximum of one hour, if more than one hour the production target will not be achieved.
\end{abstract}

Keywords: linear programming; profit; production planning; light steel

\begin{abstract}
ABSTRAK
Pemrograman linier dapat menganalisis berbagai kendala terkait dengan kondisi nyata di perusahaan dan memberikan solusi terbaik. Pada penelitian ini dilakukan perencanaan produksi baja ringan untuk 6 hari kerja, dimana terdapat 4 jenis produk baja ringan dengan ketebalan yang berbeda-beda. Dengan metode ini didapatkan penjadwalan produksi per hari dan keuntungan yang didapat selama seminggu yaitu, pada saat harga bahan baku normal maka diperoleh keuntungan sebesar Rp 179.005.800,-; saat harga bahan baku turun diperoleh keuntungan sebesar Rp 171.143.000,-, dan saat harga bahan baku naik diperoleh keuntungan sebesar Rp 205.766.400,-. Pada penelitian ini juga dilakukan beberapa skenario seperti skenario 1 mesin yang dipakai tidak boleh mengalami kerusakan pada hari pertama produksi karena target produksi tidak akan tercapai, kemudian untuk skenario 2 peningkatan jumlah permintaan sebesar $10 \%$ dan untuk skenario 3 pengurangan jam kerja diperoleh maksimal selama satu jam, jika lebih dari satu jam maka tidak akan tercapai target produksi.
\end{abstract}

Kata kunci: pemrograman liniere keuntungan; perencanaan produksi; baja ringan

\section{PENDAHULUAN}

Saat ini perkembangan dunia usaha mengalami kemajuan yang semakin pesat. permintaan pasar terhadap produk semakin besar karena semakin meningkatnya pembangunan di Indonesia, yang mengakibatkan persaingan antar perusahaan untuk dapat mengimbangi permintaan pasar. Untuk mendapatkan ketepatan jumlah produksi sesuai target perusahaan, maka setiap perusahaan perlu memperhatikan proses produksi dan diperlukan adanya koordinasi yang baik dari setiap elemen perusahaan. Produksi adalah suatu proses mengubah bahan baku menjadi barang jadi atau menambah nilai suatu produk (barang dan jasa) agar dapat memenuhi kebutuhan masyarakat (Hutajulu, 2010). Sektor perindustrian merupakan salah satu sektor yang berperan penting dalam pembangunan ekonomi nasional (Kemenperin, 2017). Industri yang berkembang akan menciptakan persaingan yang tinggi, sehingga akan berpengaruh terhadap masing-masing perusahaan untuk meningkatkan keuntungannya. Setiap perusahaan memerlukan suatu perencanaan jangka panjang untuk menciptakan masa depan usahanya melalui perubahanperubahan yang dilaksanakan sejak sekarang. Kondisi ini akan membawa dunia bisnis kepada pemikiran-pemikiran 
baru yang lebih maju untuk mengimbangi laju persaingan yang semakin ketat, yaitu dengan memaksimalkan keuntungan. Pasar baja di Indonesia saat ini dipasok baja impor dari luar negeri sebesar 70 persen. Berdasarkan data dari South East Asia Iron and Steel Institute (2018), kebutuhan baja di Cina hanya 47,8 juta ton tetapi produksinya mencapai 90,2 juta ton. Sementara baja di Vietnam kebutuhannya hanya 1,52 juta ton, tetapi produksinya mencapai 3,49 juta ton. Kelebihan produksi ini membuat dua negara tersebut menjualnya ke negara lain seperti Indonesia. Hal ini dikarenakan masih lebih tingginya permintaan daripada kapasitas produksi dalam negeri. Pada tahun 2018, kebutuhan baja di Indonesia mencapai 14 juta ton tetapi produksi baja dalam negeri hanya mencapai 5,1 juta ton (Sindonews, 2018). Persoalan yang umum dihadapi oleh perusahaan adalah bagaimana mengkombinasikan faktorfaktor produksi atau sumber daya yang dimiliki secara bersama dengan tepat agar diperoleh keuntungan maksimal dengan biaya yang minimal. Salah satu usaha yang menghadapi masalah tersebut adalah usaha baja ringan CV X. Permasalahan yang berkaitan dengan proses memaksimalkan keuntungan pada usaha baja ringan CV X merupakan proses mencari solusi optimal dalam produksi. Mengingat bahwa tingkat keuntungan, faktor-faktor produksi dan produk yang dihasilkan oleh perusahaan tersebut memiliki hubungan yang linear, maka pemecahan masalah optimasi yang digunakan adalah linear programming. Dalam memecahkan masalah, linear programming harus bisa menerjemahkan terlebih dahulu mengenai tujuan dan kendala-kendala ke dalam bentuk perumusan matematika. Seperti halnya dalam proses produksi baja ringan di CV X, yang mempunyai beberapa kendala dalam memproduksi empat jenis baja ringan berdasarkan jenis ketebalannya. CV X setiap kalinya akan memproduksi baja ringan dalam skala besar, namun pada setiap produksi dalam kurun waktu satu bulan, bahan-bahan tersebut belum dimanfaatkan secara maksimal. Ketika persediaan bahan-bahan belum dimanfaatkan secara maksimal maka keuntungan yang diperoleh pun belum maksimal. Hal ini disebabkan karena kurangnya pemahaman mengenai linear programming. Memperkirakan pembelian bahan baku merupakan cara yang dilakukan dalam perencanaan produksi CV X. Hal inilah yang menjadi salah satu penyebab faktor belum tercapainya keuntungan maksimal. Metode linear programming adalah metode perhitungan matematika yang tepat untuk memecahkan permasalahan rumit ini karena dapat berfungsi sebagai alat pengambilan keputusan yang dapat membantu perusahaan untuk mengkombinasikan variasi produk yang ada berdasarkan keterbatasan sumber daya yang dimiliki perusahaan. Dengan demikian, penggunaan metode ini diharapkan agar perusahaan dapat menghasilkan jumlah produksi yang tepat sehingga dapat memenuhi permintaan pasar.

\section{METODOLOGI PENELITIAN}

\section{Tahapan-tahapan Penelitian}

Pada penelitian ini dilakukan tahapan penelitian dengan langkah-langkah berikut:

1. Melakukan identifikasi awal mengenai permasalahan yang akan dibahas.

2. Membaca beberapa literatur dan bahan pustaka lainnya yang berguna sebagai bahan referensi atau informasi tambahan.

3. Membuat perumusan masalah berdasarkan identifikasi pada awal penelitian.

4. Menentukan tujuan yang ingin dicapai dari penelitian.

5. Mencari data yang dibutuhkan dengan melakukan survei ke pabrik secara langsung

6. Melakukan wawancara dengan pihak perusahaan mengenai data apa saja yang dibutuhkan untuk keperluan penelitian.

7. Melakukan pengolahan data dengan menggunakan metode linear programming.

8. Melakukan analisis data hasil perhitungan yang didapat dari program Lindo.

9. Menarik kesimpulan dan saran berdasarkan hasil analisis data.

Proses penelitian ini digambarkan melalui alur penelitian pada gambar 1. 


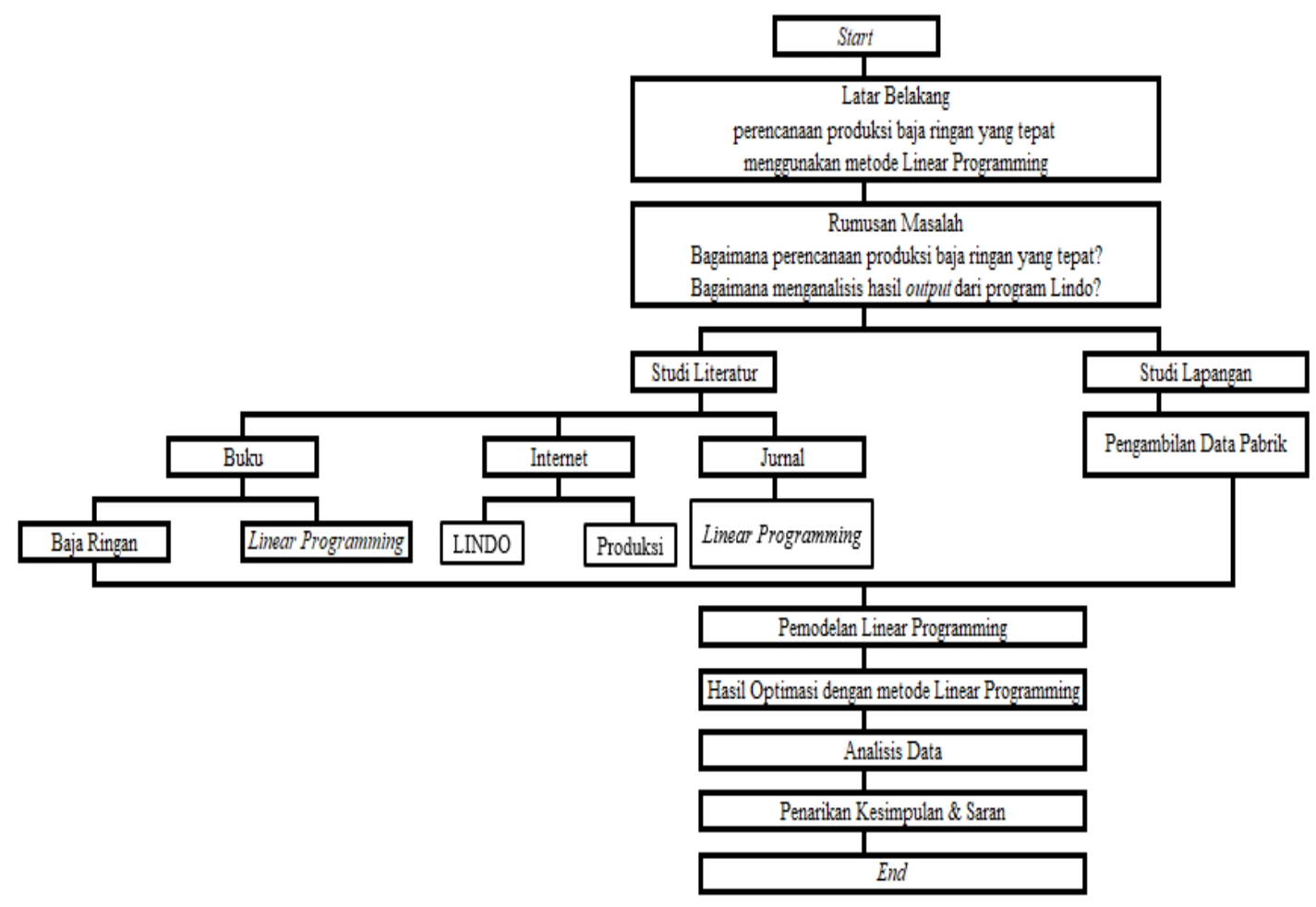

Gambar 1. Alur Penelitian

\section{HASIL DAN PEMBAHASAN}

\section{Pemodelan Data untuk Linear Programming}

Berikut adalah Decision Variables yang digunakan dalam penelitian ini:

A $\quad$ : Jumlah reng 0,3 yang diproduksi/hari

$\mathrm{B}_{1-6} \quad:$ Jumlah reng 0,35 yang diproduksi/hari

$\mathrm{C}_{1-6} \quad$ : Jumlah reng 0,4 yang diproduksi/hari

$\mathrm{D}_{1-6} \quad$ : Jumlah canal 0,45 yang diproduksi/hari

E $\quad:$ Jumlah canal 0,5 yang diproduksi/hari

$\mathrm{F}_{1-6} \quad:$ Jumlah canal 0,55 yang diproduksi/hari

$\mathrm{G}_{1-6} \quad:$ Jumlah canal 0,6 yang diproduksi/hari

$\mathrm{H}_{1-6} \quad$ : Jumlah canal 0,65 yang diproduksi/hari

$\mathrm{I}_{1-6} \quad:$ Jumlah canal 0,7 yang diproduksi/hari

$\mathrm{J}_{1-6} \quad$ : Jumlah canal 0,9 yang diproduksi/hari

K $\quad$ : Jumlah holo 0,2 (101) yang diproduksi/hari

L : Jumlah holo 0,2 (135) yang diproduksi/hari

$\mathrm{M}_{1-6} \quad$ : Jumlah spandek 0,2 (1219) yang diproduksi/hari

$\mathrm{N}_{1-6} \quad$ : Jumlah spandek 0,25 (1219) yang diproduksi/hari

Keterangan $\quad: \mathrm{A} 1=$ jumlah reng 0,3 yang diproduksi pada hari pertama

$\mathrm{A} 2=$ jumlah reng 0,3 yang diproduksi pada hari kedua

Keuntungan yang ditetapkan oleh CV X untuk setiap jenisnya berbeda-beda. Profit = total biaya produksi x persen keuntungan, sehingga keuntungan dari penjualan baja ringan adalah:

Keuntungan untuk reng 0,3

Keuntungan untuk reng 0,35

Keuntungan untuk reng 0,4

Keuntungan untuk canal 0,45

Keuntungan untuk canal 0,5

Keuntungan untuk canal 0,55

Keuntungan untuk canal 0,6

Keuntungan untuk canal 0,65

Keuntungan untuk canal 0,7

$$
\begin{aligned}
& \text { :Rp 646,-- } \\
& : \operatorname{Rp} 734,- \\
& : \operatorname{Rp} 822,- \\
& : \operatorname{Rp} 1.482,- \\
& : \operatorname{Rp} 1.658,- \\
& : \operatorname{Rp} 1.790,- \\
& : \operatorname{Rp} 1.966,- \\
& : \operatorname{Rp} 2.142,- \\
& : \operatorname{Rp} 2.274,-
\end{aligned}
$$


Keuntungan untuk canal 0,9

Keuntungan untuk holo 0,2 (101)

Keuntungan untuk holo 0,2 (135)

Keuntungan untuk spandek 0,2 (1219)

Keuntungan untuk spandek 0,25 (1219)
: Rp 2.934,-

: Rp 406,-

: Rp 533,-

: Rp 1.138,-

: Rp 1.413,-

Sehingga berdasarkan perhitungan tersebut dapat dibuat suatu persamaan linear atau yang disebut Objective Function, yaitu:

$\operatorname{Max} \mathrm{Z}=$

$646(\mathrm{~A} 1+\mathrm{A} 2+\mathrm{A} 3+\mathrm{A} 4+\mathrm{A} 5+\mathrm{A} 6)+734(\mathrm{~B} 1+\mathrm{B} 2+\mathrm{B} 3+\mathrm{B} 4+\mathrm{B} 5+\mathrm{B} 6)+822(\mathrm{C} 1+\mathrm{C} 2+\mathrm{C} 3+\mathrm{C} 4+\mathrm{C} 5+\mathrm{C} 6)$

$+1482(\mathrm{D} 1+\mathrm{D} 2+\mathrm{D} 3+\mathrm{D} 4+\mathrm{D} 5+\mathrm{D} 6)+1658(\mathrm{E} 1+\mathrm{E} 2+\mathrm{E} 3+\mathrm{E} 4+\mathrm{E} 5+\mathrm{E} 6)+1790(\mathrm{~F} 1+\mathrm{F} 2+\mathrm{F} 3+\mathrm{F} 4+\mathrm{F} 5+$

$\mathrm{F} 6)+1966(\mathrm{G} 1+\mathrm{G} 2+\mathrm{G} 3+\mathrm{G} 4+\mathrm{G} 5+\mathrm{G} 6)+2142(\mathrm{H} 1+\mathrm{H} 2+\mathrm{H} 3+\mathrm{H} 4+\mathrm{H} 5+\mathrm{H} 6)+2274(\mathrm{I} 1+\mathrm{I} 2+\mathrm{I} 3+\mathrm{I} 4+\mathrm{I} 5$

$+\mathrm{I} 6)+2934(\mathrm{~J} 1+\mathrm{J} 2+\mathrm{J} 3+\mathrm{J} 4+\mathrm{J} 5+\mathrm{J} 6)+406(\mathrm{~K} 1+\mathrm{K} 2+\mathrm{K} 3+\mathrm{K} 4+\mathrm{K} 5+\mathrm{K} 6)+533(\mathrm{~L} 1+\mathrm{L} 2+\mathrm{L} 3+\mathrm{L} 4+\mathrm{L} 5+$

$\mathrm{L} 6)+1138(\mathrm{M} 1+\mathrm{M} 2+\mathrm{M} 3+\mathrm{M} 4+\mathrm{M} 5+\mathrm{M} 6)+1413(\mathrm{~N} 1+\mathrm{N} 2+\mathrm{N} 3+\mathrm{N} 4+\mathrm{N} 5+\mathrm{N} 6)$

Berikut adalah kendala-kendala yang digunakan dalam penelitian ini:

\section{Kendala Keterbatasan Bahan Baku Baja Ringan}

Baja ringan yang tersedia digunakan untuk memproduksi berbagai macam produk yang mengalami keterbatasan bahan baku yaitu sebesar $60000 \mathrm{~kg} / \mathrm{hari}$. Contoh penulisan dalam bentuk persamaan matematis:

$1,4 \mathrm{~A} 1+1,6 \mathrm{~B} 1+1,8 \mathrm{C} 1+3,3 \mathrm{D} 1+3,7 \mathrm{E} 1+4 \mathrm{~F} 1+4,4 \mathrm{G} 1+4,8 \mathrm{H} 1+5,1 \mathrm{I} 1+6,6 \mathrm{~J} 1+0,67 \mathrm{~K} 1+0,9 \mathrm{~L} 1+2 \mathrm{M} 1$ $+2,5 \mathrm{~N} 1 \leq 60000 \mathrm{~kg}$

\section{Kendala Keterbatasan Gudang Baja Ringan}

CV X mempunyai gudang yang dapat menampung sampai 20000 batang. Contoh penulisan dalam bentuk persamaan matematis:

$0,5 \mathrm{~A} 1+0,5 \mathrm{~B} 1+0,5 \mathrm{C} 1+0,5 \mathrm{D} 1+0,5 \mathrm{E} 1+0,5 \mathrm{~F} 1+0,5 \mathrm{G} 1+0,5 \mathrm{H} 1+0,5 \mathrm{I} 1+0,5 \mathrm{~J} 1+\mathrm{K} 1+\mathrm{L} 1+0,5 \mathrm{M} 1+0,5$

$\mathrm{N} 1+0,5 \mathrm{UA} 0+0,5 \mathrm{UB} 0+0,5 \mathrm{UC0}+0,5 \mathrm{UD} 0+0,5 \mathrm{UE} 0+0,5 \mathrm{UF} 0+0,5 \mathrm{UG} 0+0,5 \mathrm{UH} 0+0,5 \mathrm{UI} 0+0,5 \mathrm{UJ} 0+$ $\mathrm{UK} 0+\mathrm{ULO}+0,5 \mathrm{UM} 0+0,5 \mathrm{UN} 0 \leq 20000$ batang

3. Kendala Penggunaan Mesin (jam kerja mesin)

Kendala penggunaan mesin yaitu jam kerja mesin adalah menyesuaikan jam kerja yang sudah ditentukan yaitu dari jam 07.30 - 17.00 dengan 1 kali istirahat selama 1 jam. Tabel 1. adalah jumlah ketersediaan mesin yang ada di pabrik:

Tabel 1. Jumlah mesin

\begin{tabular}{cc}
\hline Mesin & Jumlah \\
\hline Mesin reng & 2 \\
Mesin canal & 3 \\
Mesin holo & 1 \\
Mesin spandek & 1 \\
\hline
\end{tabular}

Durasi untuk mencetak masing-masing produk tergantung dari ketebalan masing-masing jenis (3 detik - 14 detik). Dan rumus dalam menghitung jam kerja mesin dalam memproduksi setiap baja ringan, yaitu:

Jam kerja mesin $=\quad \frac{\text { durasi pengerjaan } 1 \text { gulungan }}{\text { berat } 1 \text { gulungan } / \text { berat } 1 \text { batang }}+\frac{\text { waktu loading } 1 \text { gulungan }}{\text { berat } 1 \text { gulungan } / \text { berat } 1 \text { batang }}$

Contoh penulisan dalam bentuk persamaan matematis:

3,6 A1 + 4,2 B1 + 4,7 C1 $\leq 30600$ detik x 2 mesin

\section{Kendala Keterbatasan Jam Kerja Tenaga Kerja}

Kendala keterbatasan jam kerja tenaga kerja yaitu sesuai dengan jam operasional mesin. Setiap tenaga kerja diperkirakan membutuhkan waktu 5 detik untuk memindahkan hasil potongan ke trolley, dan jumlah pekerja yang membantu dalam memindahkan hasil potongan ada 2 orang setiap mesin. Contoh penulisan dalam bentuk persamaan matematis:

$5 \mathrm{~A} 1+5 \mathrm{~B} 1+5 \mathrm{C} 1 \leq 30600$ detik x 2 mesin $\times 2$ orang

\section{Kendala Perkiraan Permintaan}

Kendala perkiraan permintaan reng 0,3 dihitung berdasarkan permintaan bulan sebelumnya dan dibagi 24 hari (hari aktif). 
Permintaan reng 0,3

$$
\begin{aligned}
& =\frac{\text { total permintaan bulan sebelumnya }}{24 \text { hari aktif }} \\
& =\frac{36450}{24}=1520 \text { batang }
\end{aligned}
$$

Diasumsikan produksi reng 0,3 menghabiskan sisa gulungan. Satu gulungan untuk reng 0,3 adalah $700 \mathrm{~kg}$ dan berat reng 0,3 adalah $1,4 \mathrm{~kg} / \mathrm{batang}$, sehingga satu gulungan menghasilkan 500 batang.

$$
=\frac{1520}{500}=3,04 \text { gulungan } \approx 4 \text { gulungan }
$$

Contoh penulisan dalam bentuk persamaan matematis:

$\mathrm{A} 1$ - UA1 + UA0 $\geq 2000$ batang

6. Kendala Ketersediaan Baja Ringan di Gudang

CV X memiliki gudang yang terdiri dari beberapa produk jadi yang tersisa dari produksi minggu sebelumnya. Contoh penulisan dalam bentuk persamaan matematis:

$\mathrm{UA} 0=480$

\section{Hasil Nilai Optimasi Produksi Baja Ringan}

Berdasarkan hasil pengolahan data menggunakan LINDO, maka didapatkan hasil optimasi produksi pada CV X. Keuntungan yang dicapai sebesar Rp 179.005.800,- dan penjadwalan produksi pada CV X dapat dilihat pada tabel 2 sampai tabel 15 .

Tabel 2. Hasil Optimasi Produksi Baja Ringan Jenis Reng Saat Harga Bahan Baku Normal

\begin{tabular}{ccc}
\hline Jenis Produk & Hari & Jumlah Produksi \\
\hline & 1 & 1520 \\
Reng $\mathbf{0 , 3}$ & 2 & 2000 \\
(A) & 3 & 2000 \\
& 4 & 2000 \\
& 5 & 2000 \\
& 6 & 2000 \\
\hline
\end{tabular}

Tabel 3. Hasil Optimasi Produksi Baja Ringan Jenis Reng Saat Harga Bahan Baku Normal

\begin{tabular}{ccc}
\hline Jenis Produk & Hari & Jumlah Produksi \\
\hline & 1 & 1340 \\
Reng 0,35 & 2 & 1748 \\
(B) & 3 & 1748 \\
& 4 & 1748 \\
& 5 & 3496 \\
\hline
\end{tabular}

Tabel 4. Hasil Optimasi Produksi Baja Ringan Jenis Reng Saat Harga Bahan Baku Normal

\begin{tabular}{ccc}
\hline Jenis Produk & Hari & Jumlah Produksi \\
\hline & 1 & 3599,6 \\
Reng 0,4 & 2 & 0 \\
$(\mathbf{C})$ & 3 & 0 \\
& 4 & 1623,9 \\
& 5 & 272,5 \\
& 6 & 1164 \\
\hline
\end{tabular}


Tabel 5. Hasil Optimasi Produksi Baja Ringan Jenis Canal Saat Harga Bahan Baku Normal

\begin{tabular}{ccc}
\hline Jenis Produk & Hari & Jumlah Produksi \\
\hline & 1 & 190 \\
Canal 0,45 & 2 & 636 \\
(D) & 3 & 0 \\
& 4 & 0 \\
& 5 & 212 \\
& 6 & 212 \\
\hline
\end{tabular}

Tabel 6. Hasil Optimasi Produksi Baja Ringan Jenis Canal Saat Harga Bahan Baku Normal

\begin{tabular}{ccc}
\hline Jenis Produk & Hari & Jumlah Produksi \\
\hline & 1 & 560 \\
Canal 0,5 & 2 & 567 \\
(E) & 3 & 2268 \\
& 4 & 0 \\
& 5 & 0 \\
& 6 & 0 \\
\hline
\end{tabular}

Tabel 7. Hasil Optimasi Produksi Baja Ringan Jenis Canal Saat Harga Bahan Baku Normal

\begin{tabular}{ccc}
\hline Jenis Produk & Hari & Jumlah Produksi \\
\hline & 1 & 440 \\
Canal 0,55 & 2 & 1575 \\
(F) & 3 & 0 \\
& 4 & 0 \\
& 5 & 1050 \\
& 6 & 0 \\
\hline
\end{tabular}

Tabel 8. Hasil Optimasi Produksi Baja Ringan Jenis Canal Saat Harga Bahan Baku Normal

\begin{tabular}{ccc}
\hline Jenis Produk & Hari & Jumlah Produksi \\
\hline & 1 & 1280 \\
Canal 0,6 & 2 & 1431 \\
(G) & 3 & 1431 \\
& 4 & 1431 \\
& 5 & 1431 \\
& 6 & 1431 \\
\hline
\end{tabular}

Tabel 9. Hasil Optimasi Produksi Baja Ringan Jenis Canal Saat Harga Bahan Baku Normal

\begin{tabular}{ccc}
\hline & & \\
\hline & 1 & 1320 \\
Canal 0,65 & 2 & 1450 \\
(H) & 3 & 4331,8 \\
& 4 & 0 \\
& 5 & 18,2 \\
& 6 & 1450 \\
\hline
\end{tabular}

Tabel 10. Hasil Optimasi Produksi Baja Ringan Jenis Canal Saat Harga Bahan Baku Normal

\begin{tabular}{ccc}
\hline Jenis Produk & Hari & Jumlah Produksi \\
\hline & 1 & 3478,6 \\
& 2 & 0 \\
Canal 0,7 (I) & 3 & 0 \\
& 4 & 819,4 \\
& 5 & 1096 \\
& 6 & 1096 \\
\hline
\end{tabular}


Tabel 11. Hasil Optimasi Produksi Baja Ringan Jenis Canal Saat Harga Bahan Baku Normal

\begin{tabular}{ccc}
\hline Jenis Produk & Hari & Jumlah Produksi \\
\hline & 1 & 200 \\
Canal 0,9 & 2 & 1790,3 \\
$(\mathbf{J})$ & 3 & 0 \\
& 4 & 3804,1 \\
& 5 & 2833,9 \\
& 6 & 2425,7 \\
\hline
\end{tabular}

Tabel 12. Hasil Optimasi Produksi Baja Ringan Jenis Holo Saat Harga Bahan Baku Normal

\begin{tabular}{ccc}
\hline Jenis Produk & Hari & Jumlah Produksi \\
\hline & 1 & 4780 \\
Holo 0,2 (101) & 2 & 5222 \\
$(\mathbf{K})$ & 3 & 5222 \\
& 4 & 5330,9 \\
& 5 & 5884,6 \\
& 6 & 4450,5 \\
\hline
\end{tabular}

Tabel 13. Hasil Optimasi Produksi Baja Ringan Jenis Holo Saat Harga Bahan Baku Normal

\begin{tabular}{ccc}
\hline Jenis Produk & Hari & Jumlah Produksi \\
\hline & 1 & 3920 \\
Holo 0,2 (135) & 2 & 3996 \\
(L) & 3 & 3996 \\
& 4 & 3996 \\
& 5 & 3996 \\
& 6 & 3996 \\
\hline
\end{tabular}

Tabel 14. Hasil Optimasi Produksi Baja Ringan Jenis Spandek Saat Harga Bahan Baku Normal

\begin{tabular}{ccc}
\hline Jenis Produk & Hari & Jumlah Produksi \\
\hline & 1 & 1860 \\
Spandek 0,2 & 2 & 2000 \\
(1219) & 3 & 2000 \\
(M) & 4 & 2000 \\
& 5 & 2000 \\
& 6 & 2000 \\
\hline
\end{tabular}

Tabel 15. Hasil Optimasi Produksi Baja Ringan Jenis Spandek Saat Harga Bahan Baku Normal

\begin{tabular}{ccc}
\hline & 1 & 1324,2 \\
Spandek 0,25 & 2 & 3095,6 \\
$(\mathbf{1 2 1 9})$ & 3 & 3131 \\
$(\mathbf{N})$ & 4 & 1891,7 \\
& 5 & 1600 \\
& 6 & 3588,5 \\
\hline
\end{tabular}

\section{Sensitivity Analysis}

Pada penelitian ini dicari sensitivity analysis yang dapat terjadi dikarenakan hal-hal yang tidak diatur/direncanakan oleh CV X. Sebagai contoh ketika harga bahan baku naik dan bahan baku turun.

1. Perhitungan Optimasi Harga Bahan Baku Naik dan Harga Bahan Baku Turun

Harga bahan baku tentu akan mengalami kenaikan harga dan penurunan harga, dikarenakan oleh beberapa penyebab antara lain faktor ekspor-impor, situasi harga di luar negeri dan kurs dolar, dan sebagainya. Ketika harga bahan baku mengalami penurunan maka harga bisa turun mencapai Rp 10.500,-/kg, sedangkan ketika harga bahan mengalami kenaikan maka harga bisa naik mencapai $\mathrm{Rp} 12.700,-/ \mathrm{kg}$. Kenaikan harga dan penurunan harga ini dapat mempengaruhi harga jual dan pendapatan yang diterima oleh CV X. Ketika harga bahan baku naik, maka 
keuntungan yang didapat adalah sebesar Rp 205.766.400,- atau mengalami kenaikan keuntungan yang diharapkan sebesar 15\% dan ketika harga bahan baku turun, maka keuntungan yang didapat adalah sebesar Rp 171.143.000,atau mengalami penurunan keuntungan yang diharapkan sebesar 4,39\%.

\section{Skenario}

Pada penelitian ini dicoba 3 macam skenario yang sudah direncanakan / diatur. Sebagai contoh adalah kerusakan mesin cetak, kenaikan demand dan pengurangan jam kerja. Untuk skenario kerusakan mesin cetak, dilihat mesin boleh mengalami kerusakan pada hari mulai dari hari keberapa agar tetap dapat mencapai demand, kemudian untuk skenario kenaikan demand, dilihat seberapa banyak tambahan yang dapat diselesaikan dalam enam hari kerja dan untuk skenario pengurangan jam kerja, dilihat seberapa lama waktu yang digunakan untuk mencapai demand yang ada.

\section{Kerusakan Mesin Produksi}

Layaknya tubuh manusia, mesin produksi juga harus selalu dirawat. Setiap mesin produksi pasti memiliki risiko kerusakan yang bisa terjadi kapanpun (testindo, 2018). Diasumsikan pada CV X mesin yang mengalami kerusakan adalah mesin canal, mesin reng dan mesin spandek. Dibutuhkan waktu selama 3 jam untuk memperbaiki mesin yang rusak. Kerusakan mesin produksi tentu akan mempengaruhi banyaknya jumlah produksi dalam sehari dan dapat menyebabkan penambahan jam kerja/lembur untuk dapat mencapai target produksi. Berdasarkan permasalahan yang terjadi pada CV X, maka didapatkan hasil yang dapat dilihat pada tabel 16.

Tabel 16. Kondisi Mesin Produksi Baja Ringan

\begin{tabular}{ccccccc}
\hline Hari & 1 & 2 & 3 & 4 & 5 & 6 \\
\hline Mesin & $\sqrt{ }$ & - & - & - & - & - \\
\hline Canal & $\sqrt{ }$ & - & - & - & - & - \\
\hline Holo & $\sqrt{ }$ & $\sqrt{ }$ & $\sqrt{ }$ & $\sqrt{ }$ & $\sqrt{ }$ & $\sqrt{ }$ \\
\hline Spandek & $\sqrt{ }$ & - & - & - & - & - \\
\hline Keterangan: & \multicolumn{7}{l}{$\sqrt{\text { : kondisi baik }}$} & - : kondisi rusak &
\end{tabular}

Berdasarkan hasil yang sudah di trial and error, dapat dianalisis bahwa mesin holo tidak boleh mengalami kerusakan karena jumlah yang harus dihasilkan dalam satu hari sangat banyak dan memerlukan waktu yang sesuai dengan jam kerja CV X. Pada hari pertama mesin canal, mesin reng, dan mesin spandek tidak boleh mengalami kerusakan karena jumlah yang harus dihasilkan tidak mencukupi permintaan yang ada. Alternatif lain ketika mesin rusak di hari pertama maupun kedua adalah penambahan jam kerja/lembur. Jika mesin rusak pada hari kedua sampai hari keenam, produksi tetap mencapai demand yang ada dan tidak membutuhkan tambahan jam kerja/lembur. Keuntungan yang diharapkan ketika terjadi kerusakan mesin adalah sebesar Rp 164.996.500,- atau mengalami penurunan keuntungan yang diharapkan sebesar 7,8\%.

\section{Kenaikan demand}

Pada skenario kedua, demand per hari mengalami kenaikan sebanyak $10 \%$ dari total demand yang sudah ada. Berdasarkan hasil pengolahan data menggunakan LINDO, maka didapatkan hasil optimasi produksi pada CV X. Keuntungan yang diharapkan sebesar Rp 178.971.500,- atau keuntungan yang diperoleh berkurang sebesar 0,02\%.

\section{Pengurangan Jam Kerja}

Pada saat mesin bekerja selama 8 jam 30 menit, 8 jam dan 7 jam 30 menit dapat memproduksi semua jenis baja ringan. Pada saat mesin bekerja selama 7 jam, ada 1 jenis baja ringan yang tidak terproduksi sesuai demand yaitu Holo 0,2 (101). Keuntungan yang diperoleh juga semakin lama semakin menurun. Saat jam kerja mesin 8 jam 30 menit diperoleh keuntungan sebesar Rp 179.005.800,- sementara saat jam kerja mesin 8 jam diperoleh keuntungan sebesar Rp 178.246.800,- atau keuntungan yang diperoleh berkurang sebesar 0,42\% dan saat jam kerja mesin 7 jam 30 menit diperoleh keuntungan sebesar Rp 177.423.900,- atau keuntungan yang diperoleh berkurang sebesar $0,88 \%$. 


\section{KESIMPULAN DAN SARAN}

\section{Kesimpulan}

1. Berdasarkan hasil dari program LINDO, keuntungan yang diperoleh pada saat harga bahan baku normal sebesar Rp 179.005.800,-. Berdasarkan sensitivity analysis, hasil produksi per hari pada saat harga bahan baku normal berbeda dengan hasil produksi per hari pada saat harga bahan baku turun maupun naik. Keuntungan yang diperoleh pada saat harga bahan baku turun sebesar Rp 171.143.000,- atau keuntungan yang diharapkan turun sebesar 4,3\% dan keuntungan yang diperoleh pada saat harga bahan baku naik sebesar Rp 205.766.400,atau keuntungan yang diharapkan naik sebesar $15 \%$.

2. Pada CV X mesin boleh mengalami kerusakan mulai pada hari kedua. Jika mesin rusak dari hari pertama, maka target produksi per hari tidak tercapai. Berdasarkan skenario penambahan demand sebanyak $10 \%$, semua jenis produk dapat diproduksi sesuai dengan demand yang sudah ditentukan dan keuntungan yang diperoleh berkurang sebesar $0,02 \%$. Hasil produksi berdasarkan skenario pengurangan jam kerja didapat bisa menyelesaikan semua jenis berdasarkan demand per hari adalah selama 7 jam 30 menit, tetapi keuntungan yang diharapkan tidak maksimal. Keuntungan maksimal bisa dicapai dengan jam kerja yang sudah ditetapkan selama 8 jam 30 menit.

\section{Saran}

Berdasarkan penelitian yang telah dilakukan, saran yang ingin diberikan adalah diharapkan pada penelitian lebih lanjut dapat dipelajari lebih lanjut mengenai faktor-faktor lain yang berpengaruh dalam perencanaan produksi, seperti biaya gudang, biaya jam kerja lembur, kemampuan mesin yang digunakan sehingga dapat berpengaruh dalam peningkatan kecepatan produksi baja ringan tersebut.

\section{DAFTAR PUSTAKA}

Hutajulu, O.P. Kajian Peramalan Permintaan dan Perencanaan Optimasi Produksi Semen pada Plant 11 PT Indocement Tunggal Prakarsa Tbk. Bogor : Institut Pertanian Bogor, 2010.

Kemenperin. Indonesia Masuk Kategori Negara Industri. (On-Line). Tersedia di https://www.kemenperin.go.id/, 2017.

Sindonews. Baja Ringan Impor Tantangan Industri Dalam Negeri. (On-Line). https://ekbis.sindonews.com/read/1334000/179/baja-ringan-impor-tantangan-industri-dalam-negeri1535535464, 2018.

Testindo. Kerusakan Mesin Industri. (On-Line). Tersedia di https://testindo.com/article/489/kerusakan-mesinindustri, 2018. 
Optimasi Jumlah Produksi Baja Ringan Menggunakan

Willis Thedra, et al. Metode Linear Programming 